under Grant No. 552 and the Research Community of Slovenia.

Registry No. $\left(\mathrm{Xe}_{2} \mathrm{~F}_{11}{ }^{+}\right)_{2} \mathrm{NiF}_{6}{ }^{2-}, 121125-44-8$.

Supplementary Material Available: For $\left(\mathrm{Xe}_{2} \mathrm{~F}_{11}{ }^{+}\right)_{2} \mathrm{NiF}_{6}{ }^{2-}$, Tables SI and SII, listing full crystal data and details of structure determination and refinement and anisotropic temperature factors, and Figures $S 1$ and S2, showing ORTEP stereograms of the compound and its unit-cell contents (5 pages); Table SIII, listing observed and calculated structure factors ( 8 pages). Ordering information is given on any current masthead page.

Contribution from the Department of Chemistry, University of New Mexico, Albuquerque, New Mexico 87131, and Central Research and Development Department, Experimental Station, E. I. du Pont de Nemours \& Company, Wilmington, Delaware 19898

\title{
Encapsulation of Lead Sulfide Molecular Clusters into Solid Matrices. Structural Analysis with X-ray Absorption Spectroscopy
}

\author{
Karin Moller, ${ }^{\dagger}$ Thomas Bein, ${ }^{*},{ }^{\dagger}$ Norman Herron, ${ }^{\ddagger}$ Walter Mahler, ${ }^{\ddagger}$ and Ying Wang ${ }^{\ddagger}$ \\ Received December 19, 1988 \\ Molecular-size $\mathrm{PbS}$ species have been stabilized in the open-pore structure of zeolite $\mathrm{Y}$ and mordenite via ion exchange with $\mathrm{Pb}$ (II) \\ and subsequent treatment with $\mathrm{H}_{2} \mathrm{~S}$ at $295 \mathrm{~K}$. Detailed analysis of synchrotron X-ray absorption data of the $\mathrm{Pb} \mathrm{L}_{\mathrm{III}}$-edge shows \\ that intrazeolite $\mathrm{PbO}_{2}\left(\mathrm{O}_{z}\right)_{3}\left(\mathrm{O}_{z}=\right.$ zeolite oxygen) species in zeolite $\mathrm{Y}$ react with $\mathrm{H}_{2} \mathrm{~S}$ to form monomolecular $\mathrm{S}_{2} \mathrm{~Pb}\left(\mathrm{O}_{2}\right)_{3}$ species \\ that are still anchored to the zeolite framework. The intrazeolite $\mathrm{PbS}$ phase appears to be more ordered at high loading levels \\ of lead in zeolite $\mathrm{Y}$ than at low loading levels. The coordination of $\mathrm{Pb}(\mathrm{II})$ and the structure of $\mathrm{PbS}$ in the mordenite host is less \\ ordered but basically very similar to that of the monomolecular species in $Y$. Optical absorption data for these samples agree \\ very well with the structural EXAFS results. Larger PbS clusters have been stabilized in $85 \%$ ethylene-15\% methacrylic acid \\ copolymer films by a similar preparation procedure. EXAFS data indicate that the reaction forms $\mathrm{PbS}$ clusters with several $\mathrm{Pb}$ \\ coordination shells and that the conversion of $\mathrm{PbS}$ is a function of $\mathrm{Pb}(\mathrm{II})$ loading levels.
}

\section{Introduction}

Quantum size effects in small semiconductor particles have been known for two decades. ${ }^{1}$ The majority of investigations have been performed on colloids in solution, which are often subject to aggregation even if stabilizers are added. ${ }^{2-4}$ Attempts to overcome this problem are typically based upon arrested precipitation via incorporation of the semiconductor particles in more rigid environments such as glasses, micelles, polymers, or recently lipid membranes. ${ }^{5}$ When semiconductor particle dimensions are reduced, a blue shift in the absorption spectra relative to that of the bulk is generally observed. This shift is strongly dependent upon the particle size. Recently, we have shown that zeolites are useful hosts for stabilizing extremely small clusters of $\mathrm{CdS}$ and $\mathrm{CdSe}$. These clusters, which are well-defined arrangements of only a few atoms, still exhibit exciton peaks in the electronic absorption spectra, characteristic for the bulk materials. ${ }^{6-8}$ The present contribution describes an extension of these studies to the encapsulation of lead sulfide clusters in zeolites and, for comparison, in a polymer matrix. The optical properties of these CdS and $\mathrm{PbS}$ clusters in zeolite and polymer composites were reported earlier. ${ }^{9,10}$ The dependence of the band gap on PbS cluster size has been extensively studied by using $\mathrm{PbS}$ particles embedded in methacrylic acid copolymer. ${ }^{11}$ A dramatic blue shift of the absorption edge from $3200 \mathrm{~nm}$ for bulk PbS samples to $530 \mathrm{~nm}$ was shown to occur upon decreasing the particle size. The lower size limit of the PbS clusters was estimated to be smaller than $13 \AA$ by comparing the discrete features in the absorption spectra with similar spectra of CdS clusters stabilized in zeolite hosts with similar framework cavities. Here we report on the structural characteristics of $\mathrm{PbS}$ species in a variety of solid supports that, in principle, impose different spatial confinement on the growth of the semiconductor clusters. The structural information was derived from the analysis of EXAFS (extended X-ray absorption fine structure) data for the lead $\mathrm{L}_{\mathrm{III}}$ absorption edge.

\section{Experimental Section}

Lead(II) cations were exchanged into zeolites Y (Linde LZ-Y52) and mordenite (Linde LZ-M5) from an aqueous solution of $\mathrm{Pb}\left(\mathrm{NO}_{3}\right)_{2}$ at room temperature. The zeolite samples were subsequently dehydrated

\footnotetext{
University of New Mexico.

E. I. du Pont de Nemours \& Co.

Contribution No. 5008
}

Table I. Sample Compositions of Lead-Containing Zeolites and Polymers

\begin{tabular}{cll}
\hline matrix & sample name & \multicolumn{1}{c}{ stoichiometry $/$ compn } \\
\hline zeolite $\mathrm{Y}$ & $\mathrm{PbY24}$ & $\mathrm{Pb}_{24.4} \mathrm{Na}_{1.8} \mathrm{Al}_{48} \mathrm{Si}_{144} \mathrm{O}_{384}$ \\
& PbSY24 & $\mathrm{Pb}_{24.4} \mathrm{~S}_{11.2} \mathrm{Na}_{1.8} \mathrm{Al}_{48} \mathrm{Si}_{144} \mathrm{O}_{384}$ \\
& PbSY1 & $\mathrm{Pb}_{1.1} \mathrm{~S}_{1.5} \mathrm{Na}_{43} \mathrm{Al}_{46} \mathrm{Si}_{146} \mathrm{O}_{384}$ \\
mordenite & $\mathrm{PbM3}$ & $\mathrm{Pa}_{3.1} \mathrm{Na}_{0.8} \mathrm{Al}_{8} \mathrm{Si}_{40} \mathrm{O}_{96}$ \\
& PbSM3 & $\mathrm{Pb}_{3.1} \mathrm{~S}_{1.2} \mathrm{Na}_{0.8} \mathrm{Al}_{8} \mathrm{Si}_{40} \mathrm{O}_{96}$ \\
polymer & $\mathrm{PbP20}$ & $20 \mathrm{wt} \% \mathrm{~Pb}, 2.5 \mathrm{mg} / \mathrm{cm}^{2}$ \\
(E-MAA) & PbP2 & $2.0 \mathrm{wt} \% \mathrm{~Pb}, 0.25 \mathrm{mg} / \mathrm{cm}^{2}$ \\
& PbSP24 & $24 \mathrm{wt} \% \mathrm{PbS}, 3 \mathrm{mg} / \mathrm{cm}^{2}$ \\
& PbSP2.4 & $2.4 \mathrm{wt} \% \mathrm{PbS}, 0.3 \mathrm{mg} / \mathrm{cm}^{2}$
\end{tabular}

Table II. Crystallographic Data for Reference Samples and Their Utilization in the EXAFS Analysis

\begin{tabular}{|c|c|c|c|c|c|}
\hline \multirow[b]{2}{*}{ ref compd } & \multicolumn{2}{|c|}{$\begin{array}{l}\text { EXAFS Fourier } \\
\text { transform ranges }\end{array}$} & \multicolumn{3}{|c|}{ crystallographic data } \\
\hline & $k / \AA^{-1}$ & $R / \AA$ & $R / \AA$ & $N$ & ref \\
\hline $\begin{array}{c}\mathrm{Pb}\left(\mathrm{NO}_{3}\right)_{2} \\
\mathrm{~Pb}-\mathrm{O} \\
\mathrm{Pb}-\mathrm{O} \\
\mathrm{Pb}-\mathrm{N} \\
\mathrm{Pb}-\mathrm{Pb}\end{array}$ & $2.7-14.6$ & $1.5-2.6$ & $\begin{array}{l}2.81 \\
4.45,4.76,4.89 \\
3.22 \\
5.55\end{array}$ & $\begin{array}{r}12 \\
3 \times 6 \\
6 \\
12\end{array}$ & 22 \\
\hline $\mathrm{PbS}$ & & & & & \\
\hline $\begin{array}{l}\mathrm{Pb}-\mathrm{S} \\
\mathrm{Pb}-\mathrm{Pb} \\
\mathrm{Pb}-\mathrm{S} \\
\mathrm{Pb}-\mathrm{Pb}\end{array}$ & $\begin{array}{l}3.2-14.6 \\
3.2-14.6\end{array}$ & $\begin{array}{l}1.9-3.0 \\
3.5-4.5\end{array}$ & $\begin{array}{l}2.97 \\
4.20 \\
5.14 \\
5.94\end{array}$ & $\begin{array}{r}6 \\
12 \\
8 \\
6\end{array}$ & 23 \\
\hline
\end{tabular}

by slowly heating up to $673 \mathrm{~K}$ under a flow of oxygen. After cooling to ambient temperature, all samples were treated with hydrogen sulfide

(1) Berry, C. R. Phys. Rev. 1967, 161, 848.

(2) Rosetti, R.; Nakahara, S.; Brus, L. E. J. Chem. Phys. 1983, 79, 1086

(3) Fojtik, A.; Weller, H.; Koch, U.; Henglein, A. Ber. Bunsen-Ges. Phys. Chem. 1984, 88, 969.

(4) Ramsden, J. J.; Webber, S. E.; Grätzel, M. J. Phys. Chem. 1985, 89 2740.

(5) Zhao, X. K.; Baral, S.; Rolandi, R.; Fendler, J. H. J. Am. Chem. Soc. 1988, $110,1012$.

(6) Herron, N.; Wang, Y.; Eddy, M. M.; Stucky, G. D.; Cox, D. E.; Moller, K.; Bein, T. J. Am. Chem. Soc, 1989, 111, 530.

(7) Wang, Y.; Herron, N. J. Phys. Chem. 1988, 92, 4988.

(8) Moller, K.; Eddy, M. M.; Stucky, G. D.; Herron, N.; Bein, T. J. Am Chem. Soc. 1989, 111, 2564. 

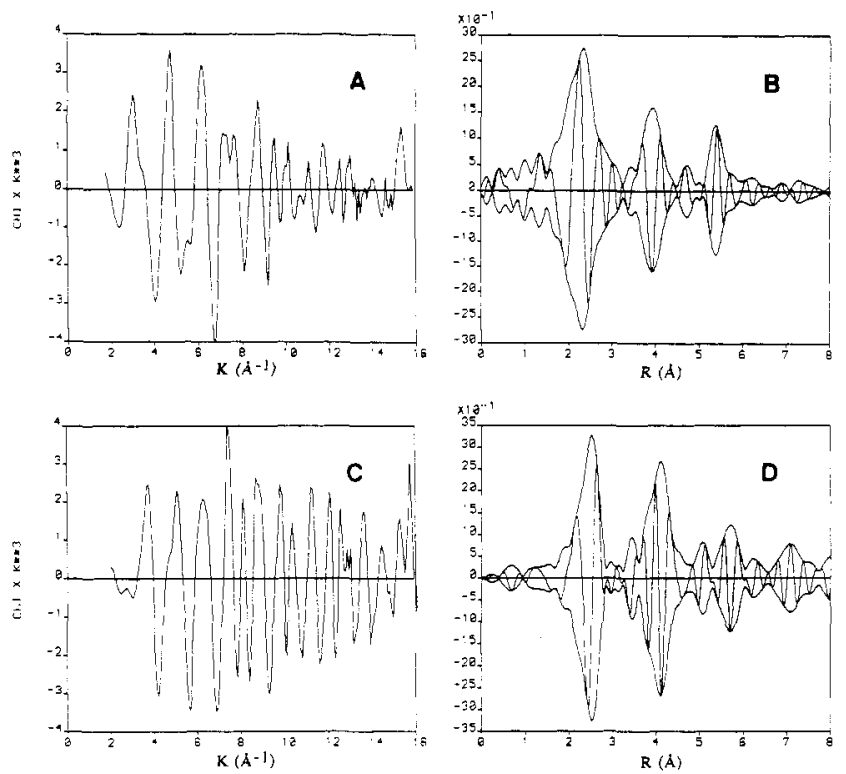

Figure 1. EXAFS data for reference samples: $(\mathrm{A}, \mathrm{C}) k^{3}$-weighted EXAFS data and (B, D) their Fourier transformations (magnitude and imaginary part) for $(\mathrm{A}, \mathrm{B}) \mathrm{Pb}\left(\mathrm{NO}_{3}\right)_{2}$ (FT range $2.7-14.6 \AA^{-1}$ ) and (C, D) $\mathrm{PbS}$ (FT range $3.2-14.6 \AA^{-1}$ ).

under controlled pressure $(1 \mathrm{~atm})$ and flow rate $(10 \mathrm{~mL} / \mathrm{min})$ for $1 \mathrm{~h}$ followed by evacuation to remove excess $\mathrm{H}_{2} \mathrm{~S}$. Color changes from white to orange/yellow were observed upon contact with the hydrogen sulfide. The concentrations of lead and sulfur were determined by atomic absorption spectroscopy (Galbraith, Knoxville, TN). The composition and sample names are listed in Table I. X-ray powder diffraction and ESCA measurements did not show any indication of the formation of bulk PbS or the presence of $\mathrm{PbS}$ on the outer surface of the zeolite crystals. The zeolite powders were stored under nitrogen atmosphere until EXAFS samples were prepared in a glovebox. A 1:1 mixture of degassed eicosane-octadecane was used to seal the zeolite samples. They were kept under nitrogen until shortly before the absorption measurements.

The polymer matrix of the polymer-trapped $\mathrm{PbS}$ particles was in all cases $85 \%$ ethylene-15\% methacrylic acid copolymer (E-MAA), 0.125 $\mathrm{mm}$ thick. The films were treated with $\mathrm{H}_{2} \mathrm{~S}$ at $295 \mathrm{~K}$ for $4 \mathrm{~h} .{ }^{12}$ Sample compositions are given in Table I. Only sample PbSP24 contained particles large enough to be detected in X-ray powder diffraction. X-ray diffraction line broadening gave an average particle size of about $4.5 \mathrm{~nm}$. All other samples did not show X-ray crystallinity. The polymer samples were stable in air and could be mounted directly in the EXAFS cell.

EXAFS experiments were carried out at the X-11A beamline at the National Synchrotron Light Source (Brookhaven, Long Island, NY) with a stored electron energy at $2.5 \mathrm{GeV}$ and ring currents between $60-120$ $\mathrm{mA}$. EXAFS data for $\mathrm{Pb} \mathrm{L}_{\mathrm{III}}$-edge $(13055 \mathrm{eV})$ were collected in transmission at about $100 \mathrm{~K}$ by using a $\mathrm{Si}(111)$ crystal monochromator. EXAFS samples were prepared such as to give a total absorption of about $\mu x=2.0$ and a step height of about 1.0 to obtain an optimal signal-tonoise ratio ( $\mu=$ absorption coefficient, $x=$ sample thickness). Phase functions and backscattering amplitudes were extracted from $\mathrm{Pb}\left(\mathrm{NO}_{3}\right)_{2}$ and $\mathrm{PbS}$ polycrystalline powders. Table II lists the Fourier transform (FT) and inverse Fourier transform (IFT) regions as used for extraction of reference data as well as crystallographic information about these compounds. $\mathrm{Pb}-\mathrm{O}$ and $\mathrm{Pb}-\mathrm{S} / \mathrm{Si}$ scatterer pairs were obtained from the first-neighbor shells of $\mathrm{Pb}\left(\mathrm{NO}_{3}\right)_{2}$ and $\mathrm{PbS}$ (Figure 1). Some samples were fitted with the second-shell $\mathrm{Pb}-\mathrm{Pb}$ contribution of $\mathrm{PbS}$ but were also compared to the other lead references to investigate a possible influence of forward or multiple scattering. The EXAFS data were analyzed by following standard procedures. ${ }^{13}$ Background removal was accomplished by applying a Victoreen fit to the preedge region and a cubic spline function to the EXAFS data. Normalization to a per-atom basis was performed by dividing the EXAFS spectrum by the height of the absorption edge. The fitting procedure is based upon the plane-wave ap-

(9) Wang, Y.; Herron, N. J. Phys. Chem. 1987, 91, 257.

(10) Wang, Y.; Mahler, W. Opt. Commun. 1987, 61, 233.

(11) Wang, Y.; Suna, A.; Mahler, W.; Kasowski, R. J. Chem. Phys. 1987, 87,7315 .

(12) Mahler, W. Inorg. Chem. 1988, 27, 435.

(13) Lee, P. A.; Citrin, P. H.; Eisenberger, P.; Kincaid, B. M. Rev. Mod. Phys. 1981, 53, 769.
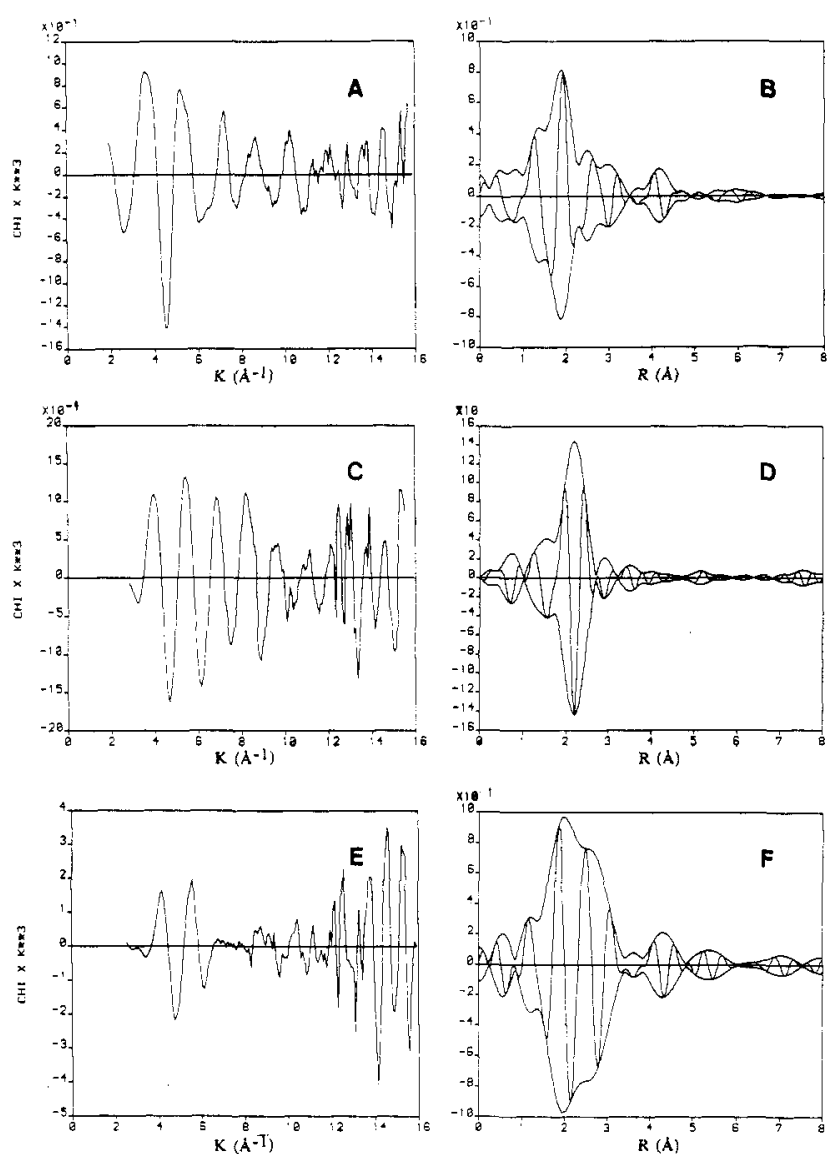

Figure 2. EXAFS data for zeolite Y samples: $(\mathrm{A}, \mathrm{C}, \mathrm{E}) \boldsymbol{k}^{3}$-weighted EXAFS data and (B, D, F) their Fourier transformations (magnitude and imaginary part) for samples (A, B) PbY24 (FT range 3.0-10.5 $\AA^{-1}$ ), (C, D) PbSY24 (FT range 3.4-11.2 $\AA^{-1}$ ), and (E, F) PbSYl (FT range $\left.3.7-9.4 \AA^{-1}\right)$.

proximation using a least-squares routine.

\section{Results and Discussion}

Lead sulfide was encapsulated into three different environments described as follows. (1) Zeolite $Y$ contains large cavities with a diameter of about $13 \AA$ and smaller cages of about $6 \AA$, which are interconnected to give a three-dimensional network of voids and channels. (2) The silica-rich and more stable mordenite structure is one-dimensional with respect to its main channels (6.7 $\times 7.0 \AA$ cross section). Smaller pockets of $3.0 \times 5.7 \AA$ diameter protrude into the channel walls in a staggered array. Both zeolite environments offer defined positions for cation siting, which may coordinate $\mathrm{Pb}^{2+}$ by two to four oxygen atoms of the zeolite framework. This siting and the rigid confinement in the zeolite channel structures make them promising hosts for identification of cluster location and restricting cluster agglomeration. (3) The third matrix, ethylene methacrylic acid copolymer, is more flexible with respect to the uptake and siting of lead cations and $\mathrm{PbS}$ cluster growth. This matrix enabled us to synthesize the whole size range of $\mathrm{PbS}$ clusters from small particulates to bulk materials, as was shown recently. ${ }^{11,12}$ Lead cations are bonded to carboxy groups of the polymer and may form entrapped $\mathrm{PbS}$ clusters upon treatment with $\mathrm{H}_{2} \mathrm{~S}$.

Of particular interest in this study are samples with lead sulfide clusters smaller than $13 \AA$ that still show semiconductor properties as observed in electronic absorption spectroscopy. The species are too small to be characterized "by normal X-ray diffraction, and they are difficult to detect by electron microscopy. In contrast, $\mathrm{X}$-ray absorption spectroscopy is sensitive to structural features with short-range order. With EXAFS it is possible not only to estimate the cluster size but also to determine the local structure around the X-ray-absorbing atom.

The EXAFS data of representative samples after background subtraction and normalization as well as their Fourier transfor- 

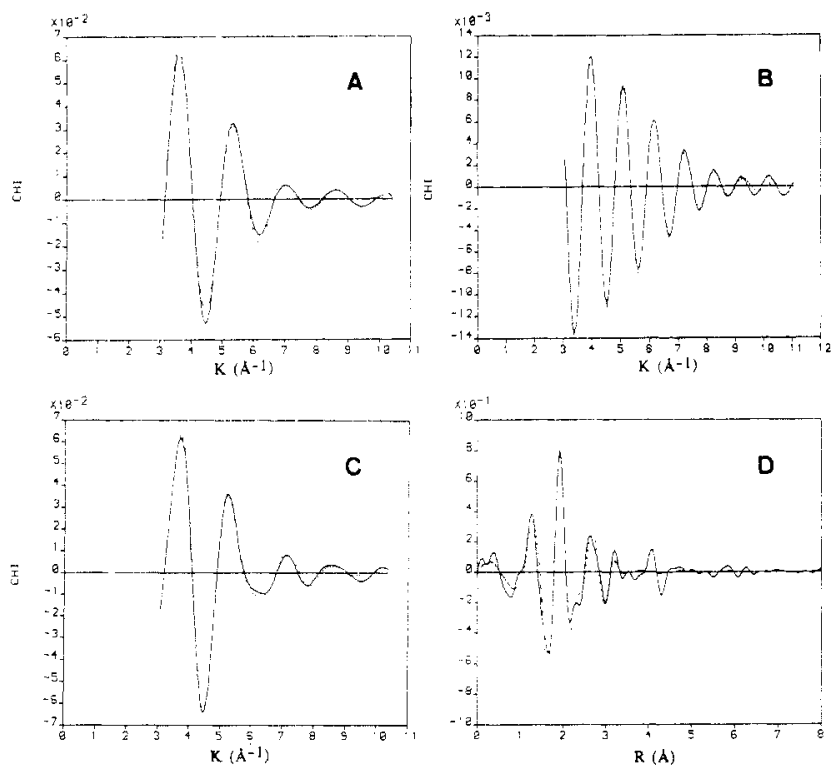

Figure 3. Sample PbY 24 experimental EXAFS data (solid line) and fit results (broken line) of the first shell: (A) IFT range 1.0-2.1 $\AA$, fitted with a single $\mathrm{Pb}-\mathrm{O}$ contribution; (B) IFT range $2.5-3.4 \AA$, fitted with $\mathrm{Pb}-\mathrm{S}$ for a single $\mathrm{Pb}-\mathrm{Si}$ contribution; (C) IFT range 1.0-3.4 $\AA$, final fit combining $\mathrm{Pb}-\mathrm{O}$ and $\mathrm{Pb}-\mathrm{Si}$; (D) Fourier transformation on the final fit where the imaginary part is compared to the experimental data.

mations (FT) are shown in Figures 2, 7, and 9. All samples were transformed after weighting with $k^{3}$ to obtain a better separation of different contributions, particularly in the first-neighbor shell. Transformation ranges are similar in all samples, allowing direct comparison of the magnitudes of the peaks as well as distances. The spectra are not adjusted for phase shifts, and all peaks appear at bond distances $0.2-0.5 \AA$ shorter than the real distances extracted from the fitting results.

Lead Sulfide in Zeolite Y. In Figure 2, the lead-exchanged zeolite Y samples are shown before (Figure 2A,B; PbY24) and after $\mathrm{H}_{2} \mathrm{~S}$ treatment (Figure 2C,D; PbSY24). Further included is a hydrogen sulfide treated sample containing a lower concentration of lead cations (Figure 2E,F; PbSY1). Several backscatterer contributions are visible in the EXAFS data of sample $\mathrm{PbY} 24$. For convenience we will refer to the range between 1 and $3.5 \AA$ as the first coordination shell, since in many samples the multiple contributions are not separated into isolated peaks. PbY24 displays a strong peak at about $2 \AA$ (not phase corrected) and a smaller one at about $3 \AA$, which could be identified as oxygen and silicon neighbors as discussed later. A peak at about $4.5 \AA$ in an outer shell may indicate the simultaneous presence of more than one lead ion in the cages of the zeolite framework. Upon treatment of this precursor with $\mathrm{H}_{2} \mathrm{~S}$, a much simpler spectrum evolves (Figure 2D), where the outer-shell feature is not present. The sample with a lower lead content (Figure $2 \mathrm{~F}$ ), corresponding to a relative excess of $\mathrm{H}_{2} \mathrm{~S}$, presents an intermediate picture with a strong overlap of several components and outer-shell features. From these initial results it is obvious that the reaction with hydrogen sulfide changes the coordination environment of the intrazeolite lead cations. Apparently, very small "molecular" lead sulfide entities are formed, since outer-shell scattering $(>3$ $\AA$ ) is absent in PbSY24

Since a convolution of peaks is still apparent in the Fourier transformations with a high weighting factor, a stepwise approach had to be undertaken for the fitting procedure. When possible, areas between about $1-2$ and $2-3 \AA$ were fit separately. These fit results were then used as initial parameters in a multiple-shell fit over the entire region of interest. Each isolated fit was tested for major improvements upon inclusion of more than one scatterer pair and distance.

Fit results for $\mathrm{PbY} 24$ are shown in Figure 3. The region between 1 and $2.1 \AA$ of the FT was fitted by using a single $\mathrm{Pb}-\mathrm{O}$ contribution (Figure 3A). Multiple-shell fits with different $\mathrm{Pb}-\mathrm{O}$ bond lengths gave no qualitative improvements. The more distant
Table III. Bond Distances $R$, Coordination Numbers $N$, Debye-Waller Factor Deviations $\sigma^{2}$, and Deviations from the Inner Potential $E$ of Lead Cations and Lead Sulfide Clusters in Zeolite Y, Mordenite, and Polymer Matrices As Derived from EXAFS Data

\begin{tabular}{|c|c|c|c|c|c|}
\hline sample & atom pair & $R / \AA^{a}$ & $N^{b}$ & $\Delta \sigma^{2} / \AA^{2}$ & $\Delta E$ \\
\hline \multirow[t]{2}{*}{$\mathrm{PbY} 24$} & $\mathrm{~Pb}-\mathrm{O}$ & 2.46 & 5.1 & 0.007 & 7.4 \\
\hline & $\mathrm{Pb}-\mathrm{Si}$ & 3.42 & (2.2) & 0.012 & 8.2 \\
\hline \multirow[t]{2}{*}{ PbSY24 } & $\mathrm{Pb}-\mathrm{O}$ & 2.47 & 3.8 & 0.013 & 5.3 \\
\hline & $\mathrm{Pb}-\mathrm{S}$ & 2.77 & 2.0 & -0.001 & -1 \\
\hline \multirow[t]{2}{*}{ PbSY1 } & $\mathrm{Pb}-\mathrm{O}$ & 2.48 & 5.0 & 0.005 & -2.3 \\
\hline & $\mathrm{Pb}-\mathrm{S} / \mathrm{Si}^{c}$ & 3.29 & $(4.3)$ & 0.008 & 4.4 \\
\hline \multirow[t]{2}{*}{$\mathrm{PbM}^{d}$} & $\mathrm{~Pb}-\mathrm{O}$ & 2.53 & 5.5 & 0.006 & 1.7 \\
\hline & $\mathrm{Pb}-\mathrm{Si}$ & 3.34 & $(0.5)$ & 0.000 & -9.6 \\
\hline $\mathrm{PbP} 20$ & $\mathrm{~Pb}-\mathrm{O}$ & 2.33 & 2.8 & 0.003 & 15 \\
\hline \multirow{2}{*}{$\mathrm{PbSP} 24$} & $\mathrm{~Pb}-\mathrm{O}$ & 2.39 & 3.3 & 0.008 & 12.4 \\
\hline & $\mathrm{Pb}-\mathrm{S}$ & 2.99 & 1.0 & 0.011 & -3.1 \\
\hline $\mathrm{PbP} 2$ & $\mathrm{~Pb}-\mathrm{O}$ & 2.37 & 3.0 & 0.001 & 16 \\
\hline \multirow{2}{*}{ PbSP2.4 } & $\mathrm{Pb} \sim \mathrm{O}$ & 2.43 & 2.1 & 0.000 & 6.8 \\
\hline & $\mathrm{Pb}-\mathrm{S}$ & 2.93 & 5.0 & 0.067 & -2.6 \\
\hline
\end{tabular}

${ }^{a}$ Error: ca. $\pm 0.03 \AA$. ${ }^{b}$ Error; ca. $\pm 30 \%$ per shell; for $\mathrm{Pb}-\mathrm{Si}$, less reliable due to multiple scattering. ${ }^{\circ}$ Convoluted shell comprising $\mathrm{Pb}-\mathrm{S}$ and $\mathrm{Pb}-\mathrm{Si}$ contributions. ${ }^{d}$ Average value of the different $\mathrm{Pb}-\mathrm{O}$ distances present in the cation positions of the mordenite structure.

region around $3 \AA$ was fitted with a $\mathrm{Pb}-\mathrm{S}$ reference, resulting in an excellent agreement between original data and fit (Figure 3B). This contribution actually arises from a $\mathrm{Pb}-\mathrm{Si}$ atom pair, showing $\mathrm{Pb}$ coordination to the zeolite lattice. A suitable $\mathrm{Pb}-\mathrm{Si}$ reference with a second-shell $\mathrm{Pb}-\mathrm{Si}$ atom pair is not available, and $\mathrm{PbS}$ was used instead. Silicon and sulfur are very close in the periodic table such that their backscattering amplitude and phase functions are almost identical. A final fit covering the whole data range of both isolated fits together is shown in Figure 3C. The good quality of the fit is further demonstrated by superimposing the imaginary part of the Fourier transformation of the experimental and calculated data as shown in Figure 3D. The fit results are listed in Table III. Each lead cation is coordinated on average to 5 oxygen atoms at $2.46 \AA$. Even though there is a vast literature about $\mathrm{X}$-ray diffraction studies of various cations in zeolite environments, no data are available about lead cations in zeolite $Y$. Lead was only studied with XRD in zeolite A. ${ }^{14}$ The zeolite A structure is comparable to that of zeolite $\mathrm{Y}$ in that it is based upon the same secondary building blocks consisting of cubooctahedra (sodalite cages). In zeolite $A$ these units are connected via four-membered-ring windows and in zeolite $Y$ via six-membered-ring windows to form a three-dimensional lattice. It was found that in dehydrated zeolite $\mathrm{A} 5$ out of $6 \mathrm{~Pb}^{2+}$ ions are located in front of the six-membered-ring windows that are common to both structures. The cations are protruding into the large cage and have a bond distance of $2.46 \AA$ to 3 oxygen atoms of the ring. In zeolite, $\mathrm{Y}$, smaller $\mathrm{Ca}^{2+}$ cations were found at $2.40 \AA$ in $\mathrm{SI}^{\prime}$ and SII six-membered-ring sites. ${ }^{15} \mathrm{Sr}^{2+}$ ions in zeolite $\mathrm{X}$ were found mostly in site SII. ${ }^{16}$ These values are very close to our own result and suggest a similar location of $\mathrm{Pb}^{2+}$ in six-membered-ring sites. The additional 2 oxygen atoms in our sample are assigned to residual water or hydroxyl groups coordinated to $\mathrm{Pb}^{2+}$, a common observation also described in the metal-zeolite systems mentioned above. Furthermore, we find an average of 2.2 silicon atoms at a distance of $3.46 \AA$. We assume that the $\mathrm{Pb}-\mathrm{Si}$ distance resulting from this fit is quite reliable (it is a typical value for cations in zeolite $Y$ ). However, due to multiple scattering, the $\mathrm{PbS}$ first-shell reference data will be less appropriate for the determination of second-shell $\mathrm{Pb}-\mathrm{Si}$ coordination numbers; thus, the resulting coordination numbers have to be considered less reliable.

An attempt was made to determine the origin of the outer-shell scattering at ca. $4.5 \AA$ (uncorrected). The amplitude function could satisfactorily be fitted with two $\mathrm{Pb}-\mathrm{Pb}$ contributions at 4.11

(14) Ronay, C.; Seff, K. J. Phys. Chem. 1985, 89, 1965.

(15) Costenoble, M. L.; Mortier, W. J.; Uytterhoeven, J. B. J. Chem. Soc., Faraday Trans 1 1978, 74, 466.

(16) Olson, D. H. J. Phys. Chem. 1968, 72, 1400. 

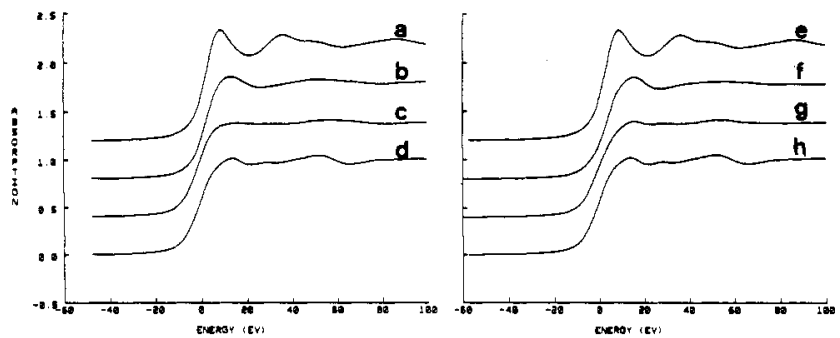

Figure 4. Normalized $\mathrm{Pb} \mathrm{L}_{\text {III }}$-edge data: (a, e) $\mathrm{Pb}\left(\mathrm{NO}_{3}\right)_{2}$; (b) $\mathrm{PbY} 24$; (c) PbSY24; (d, h) PbS; (f) PbP20; (g) PbSP2.4.
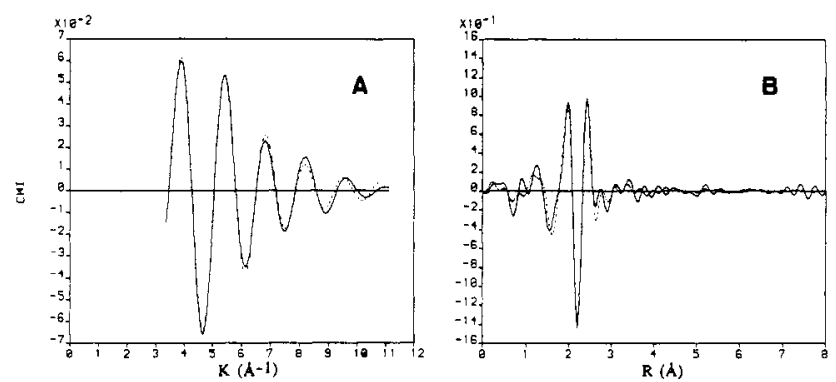

Figure 5. Sample PbSY24 experimental data (solid line) and fit results (broken line) of the first shell: (A) IFT range 1.0-2.7 $\AA$, fitted with $\mathrm{Pb}-\mathrm{O}$ and $\mathrm{Pb}-\mathrm{S}$; (B) Fourier transformation on the fit result where the imaginary part is compared the experimental data.

and $4.35 \AA$ when an inverse filtering was performed over a range of at least $1.3 \AA$. Fits with all available $\mathrm{Pb}-\mathrm{Pb}$ scatter pairs resulted in similar bond distances but gave different coordination numbers, probably due to phase shifts of reference vs unknown. Considering these limitations, it is suggested that the outer-shell peak in PbY24 is due to 2-3 lead cations occupying the same sodalite cage.

Dramatic changes in the EXAFS are observed if the lead-exchanged zeolite $\mathrm{Y}$ sample is treated with $\mathrm{H}_{2} \mathrm{~S}$ (Figure $2 \mathrm{C}, \mathrm{D}$; sample $\mathrm{PbSY} 24)$ : The outer $\mathrm{Pb}-\mathrm{Pb}$ shell contribution disappears and a significant increase of the (shifted) first-shell amplitude is observed. Furthermore, we note that the phase of the imaginary part of the first shell is inverted with respect to the first shell of sample $\mathrm{PbY} 24$. If compared with the imaginary part of $\mathrm{Pb}\left(\mathrm{NO}_{3}\right)_{2}$ and $\mathrm{PbS}$ reference data (Figure $1 \mathrm{~B}, \mathrm{D}$ ), these observations indicate that the major scattering contribution after treatment with $\mathrm{H}_{2} \mathrm{~S}$ is sulfur instead of oxygen. The $\mathrm{Pb} \mathrm{L}_{\mathrm{IIJ}}$-edge data (Figure 4) of these and all other samples confirm the interaction of $\mathrm{Pb}$ with sulfur: Edge features typical for the oxygen coordination in $\mathrm{Pb}\left(\mathrm{NO}_{3}\right)_{2}$ (Figure $4 \mathrm{a}$ ) are altered upon loading into the zeolite and dehydration. However, these zeolite coordinated cations are distinctively different from $\mathrm{PbO}$ or $\mathrm{PbO}_{2}$ edge features. ${ }^{17}$ The reaction with sulfide decreases the white line of the absorption edge such that it becomes similar to that of $\mathrm{PbS}$. However, the absence of bulk-PbS near-edge modulations in the PbS-zeolite samples point to the molecular nature of the intrazeolite $\mathrm{PbS}$ species (compare parts c (PbSY24) and d (bulk PbS) of Figure 4).

The peak between 1 and $2.7 \AA$ of sample PbSY2 4 could be simulated if a $\mathrm{Pb}-\mathrm{O}$ contribution at $2.47 \AA$ and a $\mathrm{Pb}-\mathrm{S}$ contribution of $2.0 \mathrm{~S}$ at $2.77 \AA$ were included in the fit (see Figure $5 A, B)$. The resulting bond length for the latter is unusually short for $\mathrm{Pb}-\mathrm{S}$ bonds in bulk solids $(2.97 \AA)$, but it is still longer than that of monomolecular PbS ( $2.29 \AA$; see discussion of optical data). Lead is still coordinated to an average of 3.8 oxygen atoms, indicating that almost all of the $\mathrm{Pb}$ ions remain coordinated to the zeolite after reaction with $\mathrm{H}_{2} \mathrm{~S}$. The high value of the Debye-Waller factor indicates the presence of several slightly different bond distances of $\mathrm{Pb}-\mathrm{O}$. The EXAFS results are consistent with the formation of zeolite-anchored $\mathrm{Pb}-\mathrm{S}_{2}$ species. Apparently the $\mathrm{H}_{2} \mathrm{~S}$ agent has replaced the labile water or hydroxyl ligands at the $\mathrm{Pb}$ ions, since the peak at $3 \AA$ that was assigned to $\mathrm{Pb}-\mathrm{Si}$

(17) Rao, K. J.; Wong, J. J. Chem. Phys. 1984, 81, 4832.
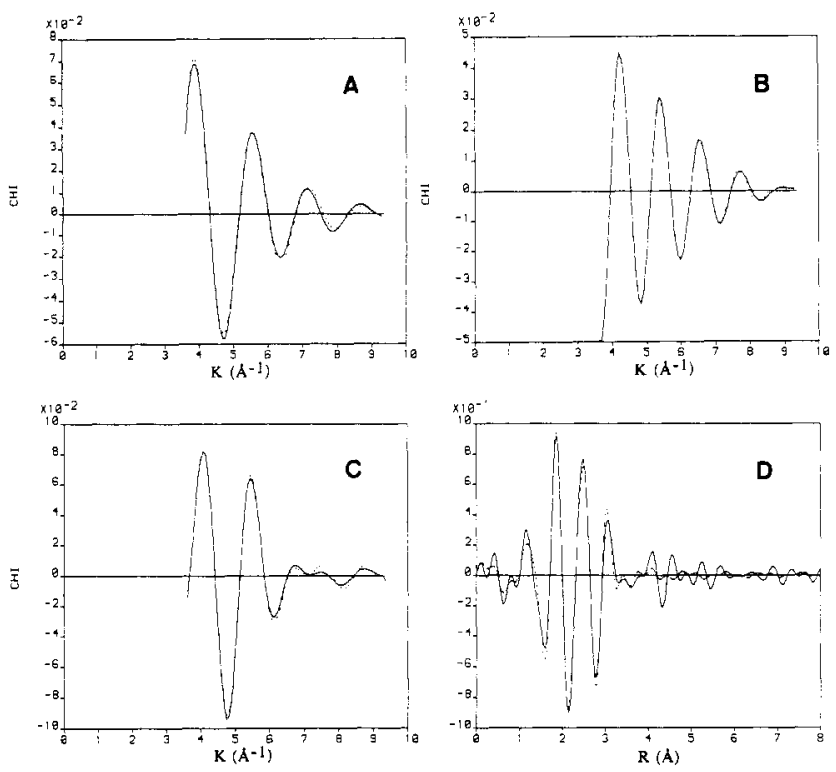

Figure 6. Sample PbSY 1 experimental data (solid line) and fit results (broken line) of the first shell: (A) IFT range 1.0-2.3 $\AA$, fitted with a single $\mathrm{Pb}-\mathrm{O}$ contribution; (B) IFT range $2.3-3.2 \AA$, fitted with a single $\mathrm{Pb}-\mathrm{S}$ contribution; (C) IFT range 1.0-3.2 $\AA$, final fit combining $\mathrm{Pb}-\mathrm{O}$ and $\mathrm{Pb}-\mathrm{S}$ scatterer; (D) Fourier transformation on the final fit where the imaginary part is compared to the experimental data.

of the zeolite framework is still present with the same magnitude. It is not clear at this point if the sulfur ligands are present as $\mathrm{H}_{2} \mathrm{~S}$, $\mathrm{HS}^{-}$, or $\mathrm{S}_{2}^{-}$, but a representative reaction can be depicted:

$$
\begin{gathered}
\left(\mathrm{O}_{2}\right)_{3} \mathrm{~Pb}(\mathrm{OH})_{2}+2 \mathrm{H}_{2} \mathrm{~S} \leftrightarrow\left(\mathrm{O}_{\mathrm{z}}\right)_{3} \mathrm{~Pb}(\mathrm{SH})_{2}+2 \mathrm{H}_{2} \mathrm{O} \\
\mathrm{O}_{2}=\text { zeolite oxygen }
\end{gathered}
$$

The complete absence of outer-shell $\mathrm{Pb}$ scattering excludes the formation of larger $\mathrm{PbS}$ crystallites in the zeolite host or any $\mathrm{Pb}-\mathrm{O}-\mathrm{Pb}$ interaction as found in the precursor sample $\mathrm{PbY} 24$. $\mathrm{On}$ the basis of the $\mathrm{Pb}-\mathrm{O}$ coordination, the $\mathrm{Pb}-\mathrm{S}_{2}$ species are located at zeolite six-ring windows. These include $\mathrm{SI}^{\prime}, \mathrm{SII}^{\prime}$, or SII positions in the sodalite or supercages. Since all these sites have very similar local coordination, the partition of the $\mathrm{Pb}$ species between these sites cannot be determined at this point.

Figure 6A-D shows results of the EXAFS analysis for the $\mathrm{PbS}$-containing sample PbSY1 in a fitting sequence similar to that used for the previously described samples. Fits on the first and second part of the first shell were performed with a single distance for $\mathrm{Pb}-\mathrm{O}$ and $\mathrm{Pb}-\mathrm{S}$, respectively. Subtle modification of the obtained parameters resulted in the final fit in Figure $6 \mathrm{C}$, Fourier-transformed in Figure 6D. The oxygen distance $(2.48$ $\AA$ ) and coordination number (5.0) are surprisingly close to those of the $\mathrm{PbY}$ precursor sample, but an additional $\mathrm{Pb}-\mathrm{X}(\mathrm{X}=\mathrm{S}$, $\mathrm{Si})$ contribution at about $3.29 \AA$ with a total coordination number of 4.3 is found. As mentioned earlier, the $\mathrm{Pb}-\mathrm{S}$ reference is used for fitting both $\mathrm{Pb}-\mathrm{S}$ and $\mathrm{Pb}-\mathrm{Si}$ contributions in the unknown. Judging from a comparison of the imaginary part and the magnitude of PbY24 and PbSY1 (Figure 2D,F), it appears that the scattering at $3.29 \AA$ for $\mathrm{Pb}-\mathrm{X}$ is a convolution of a smaller (ca. $2.9 \AA$ ) bond distance of $\mathrm{Pb}-\mathrm{S}$ and a larger distance (ca. 3.4 $\AA$ ) of $\mathrm{Pb}-\mathrm{Si}$. The outer shell is indicative of a disordered array of 2-3 $\mathrm{Pb}$ ions occupying the same zeolite cage, similar to sample $\mathrm{PbY} 24$ described earlier. It appears that the $\mathrm{PbS}$ system in the low-loading sample PbSY1 is less defined than that in the highloading sample PbSY24. These results agree very well with the optical data discussed below.

We note that there are discrepancies between the sulfur content of the zeolite samples obtained from chemical analysis and the structural results discussed above. These sulfur deficiencies were also observed with intrazeolite CdS species reported earlier ${ }^{6}$ and are probably due to the reversible nature of the reactions indicated above. Certain quantities of $\mathrm{H}_{2} \mathrm{~S}$ could escape from the samples before or during chemical analysis. 

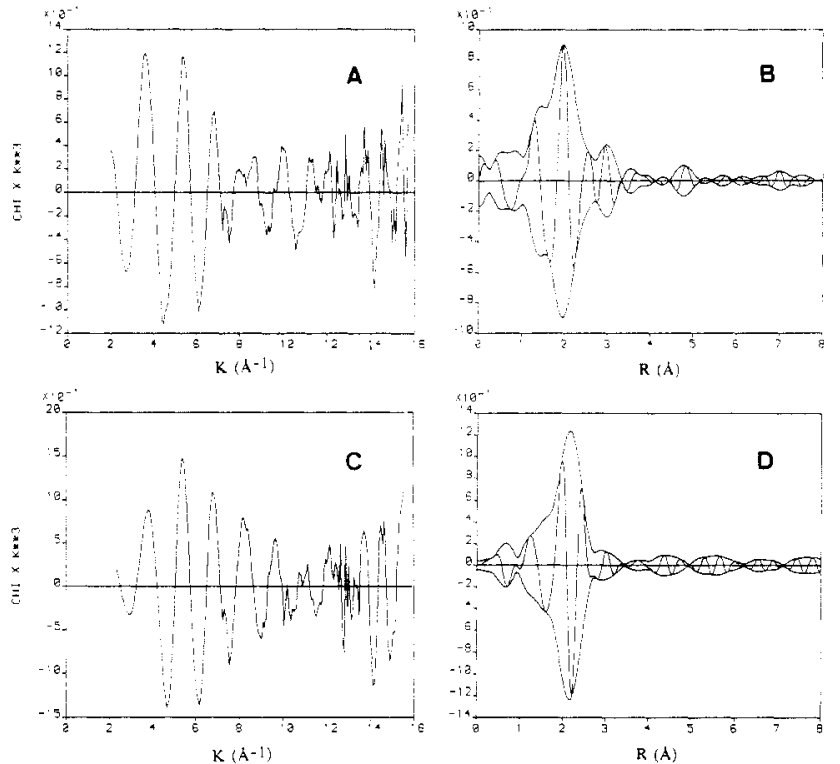

Figure 7. EXAFS data for mordenite samples: $(\mathrm{A}, \mathrm{C}) k^{3}$-weighted EXAFS data and (B, D) their Fourier transformations (magnitude and imaginary part) for samples $(\mathrm{A}, \mathrm{B}) \mathrm{PbM} 3$ (FT range $3.1-10.3 \AA^{-1}$ ) and (C, D) PbSM3 (FT range 3.3-11.2 $\AA^{-1}$ ).

Lead Sulfide in Mordenite. The experimental data and Fourier transformations of the lead-exchanged mordenite precursor and $\mathrm{H}_{2} \mathrm{~S}$-exposed sample are shown in Figure 7A-D. These data closely resemble their zeolite $\mathrm{Y}$ analogues. Average values obtained from the fitting procedure reveal 5.5 oxygen atoms at 2.53 $\AA$ and $\mathrm{Pb}-\mathrm{Si}$ coordination at $3.34 \AA$ for sample PbM3. Multiple-shell fitting for both contributions always increased the quality of the fits, but the results were very sensitive to the starting parameters. Oxygen distances from 2.39 to $2.56 \AA$ and $\mathrm{Pb}-\mathrm{Si}$ distances between 3.20 and $3.40 \AA$ provided acceptable fits. From $\mathrm{X}$-ray diffraction studies of cation-exchanged mordenites it is known that predominantly two locations are occupied by cations. For instance, $\mathrm{Na}^{+}$ions are coordinated to either four oxygens with four different bond distances between 2.59 and $2.64 \AA$ in the puckered eight-membered rings or to four oxygens at distances in the range $2.58-2.94 \AA$ in the large channel. ${ }^{18}$ For calciumexchanged mordenites a similar spread in bond distances was observed. ${ }^{19}$ If the $\mathrm{Ca}^{2+}$ mordenite was dehydrated at $573 \mathrm{~K}$, coordination to six framework oxygens and an additional water molecule was found for positions in the most populated side channel. We assume a similar distribution of distances from $\mathrm{Pb}^{2+}$ to the nearest-neighbor oxygen atoms, which prevents a detailed EXAFS analysis. Similarly, a detailed analysis of the sulfurcontaining sample PbSM3 was not warranted due to multiple coordination distances. However, the resemblance between samples PbSM3 and PbSY24 with respect to the increase in magnitudes in the first shell and the missing outer-shell features at ca. $4 \AA$ in comparison to the precursor samples, as well as the shape and location of the imaginary parts, indicates the formation of molecular-sized, anchored PbS entities of PbSM3 as well.

The combined results of the $\mathrm{PbS}$-zeolite samples indicate that accommodation of the precursor lead ions in zeolite cavities has a strong effect upon the growth of lead sulfide species. In contrast to reactions in liquids or swollen polymers, the zeolite stabilizes the siting of lead ions such that reaction with $\mathrm{H}_{2} \mathrm{~S}$ does not allow sintering of larger colloidal particles. Instead, "molecular", zeolite-anchored $\left(\mathrm{O}_{2}\right)_{3} \mathrm{PbS}_{2}$ species are formed.

Optical Absorption Spectra of PbS in Zeolites. The optical absorption spectra, obtained from diffuse-reflectance measurements, of $\mathrm{PbS}$ in zeolite $\mathrm{Y}$ at loading densities close to those of samples PbSY24 and PbSY1 are shown in Figure 8a. Spectra

(18) Schlenker, J. L.; Pluth, J. J.; Smith, J. V. Mater. Res. Bull. 1979, 14 751

(19) Elsen, J.; King, G. S. D.; Mortier, W. J. J. Phys. Chem. 1987, 91, 5800

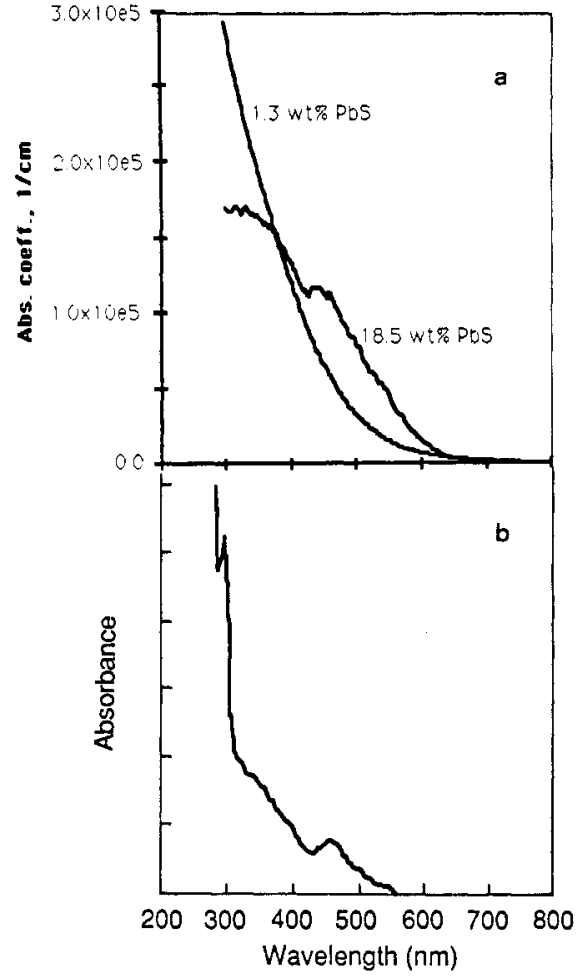

Figure 8. Optical absorption spectra of $\mathrm{PbS}$ clusters in different matrices: (a) different loadings of $\mathrm{PbS}$ in zeolite $\mathrm{Y}$ (from diffuse-reflectance measurements); (b) monomolecular PbS trapped in an Ar matrix (redrawn from ref 20 ).

of $\mathrm{PbSM}$ were reported elsewhere, ${ }^{9}$ and details of the diffusereflectance technique have been presented before. ${ }^{6}$ Important features of the absorption spectra are summarized as follows. (1) Both low-loading (1.3 wt \% Pb) and high-loading (18.5 wt \% P) samples have essentially the same optical absorption edge positions. This is in contrast to what has been observed for CdS in zeolite $\mathrm{Y}$, where the absorption spectra show a pronounced red shift from low-loading to high-loading samples. ${ }^{6}$ At low loading densities, isolated $(\mathrm{CdS})_{4}$ cubes are present in the sodalite cages, and as the loading density increases, they start to interconnect, forming a "supercluster" structure, which appears to be responsible for the red shift in the absorption spectrum. The observation that the increase in PbS loading density does not cause a shift in the absorption spectrum already suggests that $\mathrm{PbS}$ cannot exist as $(\mathrm{PbS})_{4}$ cubes and no extended supercluster structure is formed at high loading density. (2) The absorption spectrum of $\mathrm{PbS}$ in zeolite $Y$ at high loading densities shows distinctive, broad peaks at ca. 450 and $350 \mathrm{~nm}$, which coincide with the absorption peaks of monomolecular $\mathrm{PbS}$ trapped in rare-gas matrices ${ }^{20}$ (Figure $8 \mathrm{~b}$ ). These two observations, combined with the EXAFS data, provide convincing evidence that $\mathrm{PbS}$ exists mostly as molecular species in zeolite $\mathrm{Y}$. The inability of $\mathrm{PbS}$ to form a $(\mathrm{PbS})_{4}$ cube in the sodalite cage as in the case of CdS may be related to the larger lattice constant of $\mathrm{PbS}, 5.94 \AA$, compared to $5.82 \AA$ of cubic CdS. On the other hand, monomolecular $\mathrm{PbS}$ has a shorter bond length of $2.29 \AA .{ }^{21}$ We also note that the $\mathrm{Pb}_{2} \mathrm{~S}_{2}$ dimer already has a bond length approaching that of the bulk..$^{20}$ One curious difference between the low-loading and the high-loading $\mathrm{PbS} /$ zeolite $\mathrm{Y}$ samples is that the absorption spectrum of the low-loading sample does not show the distinctive monomolecular $\mathrm{PbS}$ peaks as the high-loading sample does (Figure 8). At present we suggest the following interpretation: The ion-exchange sites are different for

(20) Teichman, R. A., III; Nixon, E. R. J. Mol. Spectrosc. 1975, 54, 78.

(21) Huber, K. P.; Herzberg, G. Molecular Spectra and Molecular Structure IV. Constants of Diatomic Molecules; Van Nostrand: New York, 1979.

(22) Nowotny, H.; Heger, G. Acta Crystallogr. 1986, C4, 133

(23) Wyckoff, R. W. G. In Crystal Structure; John Wiley: London, 1963; Vol. $1, \mathrm{p} 89$. 

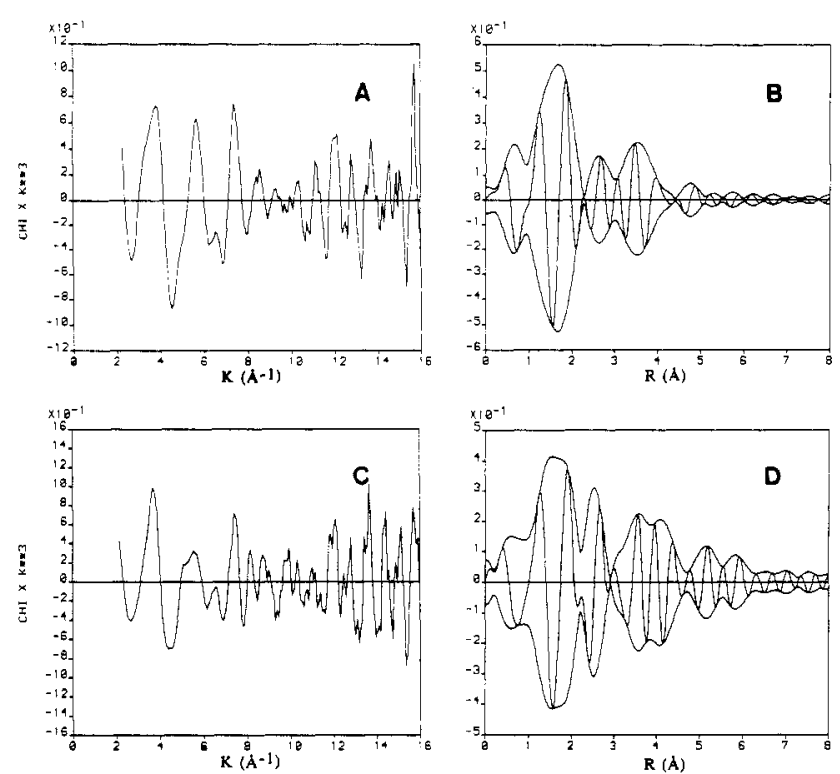

Figure 9. EXAFS data for polymer samples with high $\mathrm{Pb}$ doping: (A, C) $k^{3}$-weighted EXAFS data and (B, D) their Fourier transformations (magnitude and imaginary part) for samples (A, B) PbP20 (FT range 3.0-10.2 $\AA^{-1}$ ) and (C, D) PbSP24 (FT range 3.1-10.2 $\AA^{-1}$ ).

low-loading and high-loading samples. At low loading densities, most of the $\mathrm{PbS}$ species are located inside the sodalite cages, coordinated to and interacting with the lattice oxygen atoms. The EXAFS data of PbSY1 indicate a high oxygen coordination number even after $\mathrm{H}_{2} \mathrm{~S}$ treatment, which is potentially due to $\mathrm{H}_{2} \mathrm{O}$, $\mathrm{OH}^{-}$ligands still present in these cages. A distribution of local structural arrangements in the sodalites can average out the distinctive electronic absorption features of molecular $\mathrm{PbS}$. At higher loading densities, some $\mathrm{PbS}$ species are necessarily located in the supercages because of the inability of the sodalite cages to accommodate all $\mathrm{PbS}$. These $\mathrm{PbS}$ species in the supercages are relatively free, with less constraints from the environment; thus, the more ordered structure gives rise to the observed absorption peak.

Polymer-Trapped Lead Sulfide Particles. Normalized EXAFS data and their $k^{3}$-weighted Fourier transformations (FT) of lead-exchanged and $\mathrm{H}_{2} \mathrm{~S}$-treated polymer samples at high doping levels are shown in Figure 9. If these Fourier transformations are compared with those of zeolite-encapsulated lead and lead sulfides, a dramatic increase of strong outer-shell scattering is evident in the polymer samples. The backbone structure of polymers is more flexible than the rigid inorganic framework of zeolites, and the cluster size of the semiconductor guests now depends strongly upon the metal concentration and heat treatment. It is evident from the FT's that the cluster sizes of $\mathrm{PbS}$ in the polymer samples considered here are much larger than those of the molecular entities found in the zeolites. The data analysis (results are shown in Table III) of the polymers was performed by using an approach similar to that for the zeolites, but due to the complexity of the outer shells, quantitative analysis was limited to the first shell. Fit results for the first shell of the precursor $\mathrm{PbP} 20$ indicate that the nearest peak is due to about 3 oxygen neighbors at $2.33 \AA$, corresponding to lead cations coordinated to the carboxy groups of the methacrylic acid. It appears that the heat treatment reduces the oxygen coordination to unusually low numbers, resulting in species such as $\mathrm{HO}-\mathrm{PbOOC}$-polymer. A similar oxygen coordination is found in all samples even after treatment with $\mathrm{H}_{2} \mathrm{~S}$. The noticable outer-shell scattering of the $\mathrm{Pb}$ (II)-exchanged polymer samples is probably due to the formation of $\mathrm{PbO}$ particles.

If the lead-polymer sample is exposed to hydrogen sulfide, a significant increase in the magnitude of the outer shells is visible (Figure 9D; sample PbSP24). A fit of the nearest coordination range between 1 and $2.7 \AA$ indicates that the first oxygen coordination to lead is almost unchanged at $\mathrm{Pb}-\mathrm{O}=2.39 \AA$ (coordination number $N=3.3)$. A new contribution from $\mathrm{Pb}-\mathrm{S}(N$ $=1.0)$ arises at a distance of $2.99 \AA$. This distance is very close to the bulk value of cubic PbS (2.97 $\AA$ ). The low average coordination number is due to incomplete conversion of the lead ions to $\mathrm{PbS}$. A comparison of the imaginary part of PbSP24 with that of the bulk $\mathrm{PbS}$ reference shows good agreement for the more distant peaks. Fit results of the first shell of the precursor PbP2.4 with a lead concentration of only $2.4 \mathrm{wt} \%$ and the fit results of $\mathrm{H}_{2} \mathrm{~S}$-treated PbSP2.4 are, in general, comparable to their higher loading counterparts. The main difference is a slight contraction of bond lengths of the $\mathrm{PbS}$ phase with respect to bulk values ( $\mathrm{Pb}-\mathrm{S}$ $=2.93$ vs $2.97 \AA$ in bulk $\mathrm{PbS}$ ) and a much higher average sulfur coordination number of 5.0 in $\mathrm{PbSP} 2.4$, as compared to 1.0 in $\mathrm{PbSP} 24$. The edge features of the polymer samples are closer to those of bulk $\mathrm{PbS}$ as are those of the zeolite samples (see Figure $4 \mathrm{~g}$ ).

The EXAFS results of the polymer-supported lead phases are consistent with the following interpretation: Ion exchange with $\mathrm{Pb}^{2+}$ into the swollen ionomer and heating produce the leadcontaining polymer precursor film. The heat treatment reduces the water content such that low coordination between $\mathrm{Pb}^{2+}$ and oxygen results. Due to limited permeability of the polymer, the subsequent reaction of this composite with $\mathrm{H}_{2} \mathrm{~S}$ is primarily limited to the surface layer of the polymer. From the nearest $\mathrm{Pb}-\mathrm{S}$ coordination in sample PbSP24 it can be estimated that about $15 \%$ of the lead has formed $\mathrm{PbS}$ particles, while in sample PbSP2.4 the conversion is about $85 \%$. The origin of this difference is probably related to a higher relative excess of $\mathrm{H}_{2} \mathrm{~S}$ in the preparation procedure for the latter sample.

\section{Conclusion}

The encapsulation of lead cations into the solid matrices of zeolite $\mathrm{Y}$ and mordenite as well as polyethylene-methacrylic acid copolymer and subsequent treatments with $\mathrm{H}_{2} \mathrm{~S}$ are successful methods for imposing size limitations on the particle growth of $\mathrm{PbS}$ clusters. Zeolitic environments restrict the formation of $\mathrm{PbS}$ to the molecular level. Therefore, the different dimensionality of the channel system of zeolite $\mathrm{Y}$ and mordenite (3D and ID) has no influence on the formation of a possible superstructure of the $\mathrm{PbS}$ phase. As in analogous systems such as intrazeolite CdS or $\mathrm{CdSe}$, it is found that the semiconductor species are strongly interacting with the host lattice. Lead is anchored to the zeolite framework and simultaneously coordinated to two sulfur atoms. These results agree well with optical absorption data for the $\mathrm{PbS} /$ zeolite systems. In the polymers, larger $\mathrm{PbS}$ particles are formed with bond distances comparable to those of bulk PbS. The structural EXAFS results clearly demonstrate the confinement and local bonding correlation of lead sulfide in a crystalline, porous environment.

Acknowledgment. Support provided by the Sandia University Research Program (DOE; T.B.) is gratefully acknowledged. We thank Professor D. E. Sayers for valuable discussions. The operational funds for NSLS beamline X11A are provided by DOE Grant No. DE-ASO580ER 10742.

Registry No. $\mathrm{Pb}, 7439-92-1 ; \mathrm{H}_{2} \mathrm{~S}, 7783-06-4 ; \mathrm{PbS}, 1314-87-0$. 